\title{
Variation in Students' Conceptions of Self-Assessment and Standards
}

\author{
Heng Kiat Kelvin Tan, ${ }^{1}$ Chua Tee Teo, ${ }^{2}$ and Chee Shen $\mathbf{~ g g}^{3}$ \\ ${ }^{1}$ Policy and Leadership Studies, National Institute of Education, Nanyang Technological University, 1 Nanyang Walk, \\ Singapore 637616 \\ ${ }^{2}$ Psychological Studies, National Institute of Education, Nanyang Technological University, Singapore 637616 \\ ${ }^{3}$ Innova Junior College, 21 Champions' Way, Singapore 737902
}

Correspondence should be addressed to Heng Kiat Kelvin Tan, kelvin.tan@nie.edu.sg

Received 15 September 2010; Revised 10 January 2011; Accepted 9 February 2011

Academic Editor: Stephen Yang

Copyright (C) 2011 Heng Kiat Kelvin Tan et al. This is an open access article distributed under the Creative Commons Attribution License, which permits unrestricted use, distribution, and reproduction in any medium, provided the original work is properly cited.

\begin{abstract}
This paper reports the results of a phenomenographic study on the different ways that secondary students understood and utilized student self-assessment and how various ego types could affect the accuracy of self-assessment. The study sought to contribute to the growing literature which recognizes the critical role that students play in assessment processes, and in particular the different roles that they assume in student self-assessment. The results of the study provide insights into how different students experience self-assessment by articulating the variation in the perception and purposes of assessing one's own learning. This variation is depicted as a hierarchy of logically related students' conceptions of self-assessment.
\end{abstract}

\section{Introduction}

Self-assessment is inevitable and spontaneous every time a student receives a marked test script. Student self-assessment is recognized as providing concrete opportunities for students to assume responsibility for their learning through making assessment decisions and judgments [1]. A few studies have found positive effects of self-assessment on the students' performance and learning [2-4]. However, the capacity of students to judge their learning against prescribed standards may be influenced by each student's ego and confidence. When the student self-assesses, s/he makes a comparison of a particular aspect of the self with respect to an external standard like the ability of a fellow student or a particular grade to be achieved. This in turn may enhance or deflate the ego, and the student may feel more motivated to work towards his personal goal or become learnt helpless as a result. Several decades ago, researchers have been conducting studies on how to improve the accuracy of self-assessment or its predictive validity [5-7]. Results of a recent study by Lew et al. [8] where multiple judgments by self, peers, and tutors were correlated, suggested at best weak to moderate accuracy in student self-assessment. Inaccuracies in self-assessment may result in the student setting erroneous new learning goals. In this context, a research study funded by a Nanyang Technological University Start up Grant (Grant no. RP 15/06 THK) investigated the self-assessment and ego capacities of secondary students. This study hypothesizes that the student's ego is a hindrance to accurate self-assessment.

In this study, the ego refers to the "I" or self of any person [9], and to be egoistic is to have self-conceit and self-importance. In psychoanalysis, the ego is related to the superego and the id. While the ego is conscious psyche, the superego is only partly conscious and the id unconscious [9-11]. The superego is part of the personality representing the conscience, and it is formed early in life by internalizing the moral standards of parents and rules of society $[9,11]$. It restrains the ego and controls the impulses of the id $[11,12]$. The id is the source of instinctive impulses that seeks satisfaction according to the pleasure principle; these impulses are modified by the ego and the superego before they are given overt expression [9]. According to Freud (as cited in [13]), a narcissistic person suffering from obsessivecompulsive disorder thinks that he is especially clean or extremely conscientious as he is flattered by self-love. It is interesting to note that the self-assessment factor was lacking 
in the case study of a patient with obsessive-compulsive neurosis [13]. Egocentric thinking, which arises from the ego and self-serving perspectives, is known to interfere with critical thinking [14]. Individuals who routinely practise egocentric thinking often use self-centred psychological standards, rather than objective intellectual standards, to determine what to believe and what to reject. This study foreshadows the possibility that egoistic or narcissistic persons may have problems with the accuracy of self-assessment.

Educators understand that the student's self-image, including the ego, is affected by schooling practices which directly bear judgment on the student's competence. In particular, unilateral assessment practices may reduce students to being vulnerable objects of testing. Such practices encapsulate the systemic power practices which undermine students' self-image and self-belief. Self-assessment helps students to become more realistic as they reflect on their performance. They may also become motivated to improve since they are forced to reflect on what is necessary to improve their learning outcomes.

It has been popular to advocate student self-assessment practices as a means of "empowering" students in the assessment process. The conventional argument has been that self-assessment counters the dominant influences of the teacher's power by allowing students to exercise some of that power for themselves. In this regard, reducing the teacher's power over students is a basis for the practice of student selfassessment [15].

However, there is a growing recognition that student self-assessment may discipline rather than empower students $[15,16]$. Likewise, it can be surmised that student selfassessment practices may dent students' self-confidence and affect their subsequent self-assessment ability. Whilst there have been studies on the effect of gender, subject disciplines and academic year level on self-assessment reliability, the effect of the students' ego in student self-assessment remains unexplored and underemphasized.

This paper reports the results of a phenomenographic study on the different ways that secondary students understood and utilized student self-assessment and how various ego strengths affected the accuracy of self-assessment. The study sought to contribute to the growing literature which recognizes the critical role that students play in assessment processes, and in particular the different roles that they assume in student self-assessment. The results of the study provide insights into how different students experience selfassessment by articulating the variation in the perception and purposes of assessing one's own learning. This variation is depicted as a hierarchy of logically related students' conceptions of self-assessment.

\section{Methodology}

Phenomenography has been credited as "an internationally valued educational research method since the 1970s" [17]. As an approach to qualitative research, phenomenography is the process of describing variations in peoples' experiences of phenomenon through their own discourse. Its aim is to investigate and present "the qualitatively different ways in which something is experienced" [18]. The ultimate goal of phenomenography is to describe the qualitatively different ways in which we understand our experience of phenomena in the world around us [19]. Phenomenography is about the description of things (phenomenon) as they appear to us. Its characteristic outcome is a description of the qualitatively different ways that a group of individuals experience a phenomenon. Marton \& Booth [20] describe the basis of phenomenography as "an interest in describing the phenomena in the world as others see them, and in revealing and describing the variation therein, especially in an educational context." (page 111).

Phenomenography assumes a life-world, a coconstituted reality where human beings and the world are inseparably related to each other [21]. In contrast, a dualist philosophy considers individuals to be separate from the phenomenon or object of study. For example, a cognitivistic philosophy considers the reality of a phenomenon to be external of the individual. Concepts can be understood independently of the persons who perceive them. An individual gains knowledge of phenomena through the mind by processing information that is received from an external reality. In this dualistic perspective, the individual and the phenomena in the world are considered as separate entities.

A nondualist philosophy sees individuals and the phenomenon as being inseparable. In phenomenography, no distinction is made between the world and the individual who experiences the world [20]. The object of research in phenomenography is therefore the phenomenon as experienced as individuals, rather than a phenomenon that exists separately outside of individuals.

A nondualist approach to alternative assessment would therefore argue that it is insufficient to rely on official pronouncements of how alternative assessment should be defined and understood, but that such official declarations should be supplemented with an understanding of how alternative assessment is actually experienced by teachers and students. Hence, phenomenography does not seek to make statements about the world, nor statements about people. Phenomenographic statements instead are "statements about the world as experienced by people" [20, page 118]. Phenomenographic research is portrayed as a set of categories of description which represent the different ways of experiencing the researched phenomenon. The entire set of categories of description is known as the outcome space. The categories of description within each outcome space represent the variation of the individuals' experience of the phenomenon. Phenomenographic categories of description may be analysed as being logically related to one another, typically in the form of a nested hierarchy [20] or they may be analysed as branched relationships (Åkerlind, [22]).

Differences in ways of experiencing a phenomenon are typically described as categories of description or conceptions of that phenomena. Conceptions represent a researcher's analysis and description of variation in the pooled accounts of ways of experiencing the phenomenon. They represent the researcher's attempt to formalise his or her understanding of the participants' experiences of the phenomenon [23]. Each individual conception represents 
the critical aspects of one way of experiencing the phenomenon. Phenomenographic researchers typically refer to their entire set of findings for each researched phenomenon as the "outcome space". A set of conceptions (the outcome space) needs to satisfy three criteria according to Marton and Booth [20].

(i) Each conception should denote a distinctly different aspect of the experience of the phenomenon.

(ii) A logical relationship, commonly hierarchical, should exist between the different conceptions.

(iii) The outcome space should consist of the minimum number of different conceptions required to describe the critical variation in experience in the population of interest.

\section{Method}

The purpose of the study is to obtain a sense of the variation of the ways in which students of various ego levels or ego strengths in secondary schools experienced self-assessment if their learning. Fifteen students from 3 secondary schools with a range of ego scores were interviewed on their experiences of self-assessment in the following subjects: English, Mathematics, and Science.

All students were administered a newly devised Ego Checklist [24] on a 9-point Likert scale with 56 questions. The students were not aware that the questionnaire measures their ego levels. The Ego Checklist [24] consists of selfreporting statements with two main subscales called Ego 1 and Ego 2. Ego 1is measured by 18 items and has a Cronbach alpha of.86. It measures ego strength using attributes of self-confidence, perseverance, and determination in task accomplishment. Ego 2, with 9 items and a Cronbach alpha of 0.77 , measures the egoistic self or self-centredness. Ego in this study is taken as a combination of Ego 1 and Ego 2. A person high in Ego 1 and Ego 2 will be categorized as a person with high ego strength. A person with moderate scores in both Ego 1 and 2 will be classified as having medium ego strength. An individual score for each ego, namely, for Ego 1 and Ego 2, is then computed separately for each student. A total or composite score for each student was obtained by adding his Ego 1 score to his Ego 2 score.

The maximum possible score for each ego subscale was evenly divided into three portions to represent three ego strengths of "low-ego (LE)", "moderate-ego (ME)", and "high-ego (HE)". Students who obtained ego scores in the high-ego range for both Ego 1 and Ego 2 are classified as having "high ego"; those who obtained ego scores in the middle range for both ego subscales are classified as having "moderate ego", and finally those with low scores for both subscales are classified as having "low ego". There were students who had high scores for Ego 1 and middle scores for Ego 2, and vice versa. The profiles of some students were not totally clear as there were overlaps. It has to be noted that there were students who had different Ego 1 and Ego 2 scores. These had been excluded for the interviews as far as possible. Only students who had clearly defined high, medium, and low scores were identified for the interviews with the researchers.
Students who obtained ego scores in the section nearest the minimum score were categorised as having low ego scores.

Students with low ego scores were supposedly more timid, humble, and less self-centred. Those with high ego scores were probably very confident, strongwilled, and goaldirected. Those with moderate ego scores were likely to be not highly confident, not totally selfless and would follow the crowd and chose to do what the majority of the student population did. This paper reports the results of a study that examined the self-assessment process, and how it is affected by the ego. It investigates students' construction of selfassessment based on different levels or types of ego. A sample of students $(n=15)$ of three ego levels (low, moderate, and high) were interviewed separately on the ways in which they had experienced student self-assessment.

\section{Analysis}

The primary question which underpinned the individual student interviews was "what was important to each student about his or her experience of self-assessment?" The intention was to understand what the interviewees emphasized as being important in their individual experiences. In contrast, the analysis of the transcripts focused on the collective awareness of the fifteen students.

Through a reiterative process, segments in each transcript which conveyed a particular meaning or point about self-assessment were identified. Each segment was given a tentative heading and a short summary. Recurring headings were noted and eventually categories of transcript segments with similar headings were formed. Repeated readings of the transcript segments against its category's headings changed the constitution of the categories. Categories were added or removed when they could not be substantiated by their constitutive segments.

The analysis yielded 3 qualitatively different conceptions of self-assessment which emphasise compliance, reliance, and defiance. The three conceptions formed a coherent set of qualitatively different conceptions, and are labeled as compliant, reliant, and defiant conceptions of self-assessment.

\section{Results}

Three conceptions of self-assessment amongst students were identified, and it was found that each conception of selfassessment could vary with the ego levels of the students. The three conceptions are (1) compliant: self-assessment comprising students with ego levels 69-122, (2) reliant: selfassessment comprising ego levels 72-83, and (3) defiant: selfassessment comprising ego levels 116-185.

Table 1 summarises the findings of this phenomenographic study in terms of a nested hierarchy of conceptions.

Conception 1: Compliant Self-Assessment. In this conception, students typically accept their teacher's expectations for their assessment and use such expectations to judge their own learning. There is little, if at all any, understanding or emphasis on the standards and criteria for which students are 
TABLE 1: The structure of students' conceptions of self-assessment and standards.

\begin{tabular}{|c|c|c|}
\hline Compliant self-assessment & Reliant self-assessment & Defiant self-assessment \\
\hline Focus on Teacher's expectations & Focus on Teacher's standards & $\begin{array}{l}\text { Focus on judging own standards against } \\
\text { teacher's standards }\end{array}$ \\
\hline \multirow[t]{3}{*}{$\begin{array}{l}\text { (i) Accepts teacher's expectations and } \\
\text { judgment }\end{array}$} & $\begin{array}{l}\text { (i) Understands and accepts teacher's } \\
\text { expectations and judgment }\end{array}$ & $\begin{array}{l}\text { (i) Understands but does not necessarily } \\
\text { accept teacher's expectations and judgment }\end{array}$ \\
\hline & $\begin{array}{l}\text { (ii) Understands and relies on teacher's } \\
\text { interpreted standards and criteria }\end{array}$ & $\begin{array}{l}\text { (ii) Understands teacher's interpreted } \\
\text { standards and criteria }\end{array}$ \\
\hline & & $\begin{array}{l}\text { (iii) Understands self-interpreted standards } \\
\text { and judges this against teacher's standards in } \\
\text { self-assessment }\end{array}$ \\
\hline
\end{tabular}

to judge their own learning against. Instead, students seek to judge whether their learning has complied with the personal expectations of their teacher, rather than judge their learning against the requisite standards and criteria for the assessed task.

The teacher-student relationship in this conception may be illustrated by Figure 1 .

Students with a compliant conception of self-assessment accept their teacher's expectations and judgement without question. The teacher determines the standards; the students make meaning of their academic performance by accepting the grades given by the teacher.

There is no attempt on the students' part to understand what standards and criteria should mean for the assessed task. Students with a compliant conception of selfassessment do not show any awareness, nor interest, in the standards and criteria of the self-assessed task. They accept, without question, the teacher's expectations for their assessment and base their self-assessment of their work on the teacher's expectations rather than on the standards and criteria of the task. Students lack confidence in their ability to judge their work and look towards their teachers to judge the quality of their work.

Student (9): Our teacher suggested writing one article and showing it to him, and he would tell us what we should do and what we are lacking of. And the teacher we showed our final article to was the teacher who left then after. He told us that it's good and we can hand that article in, so we thought maybe we would do well in it, but it turned out otherwise. We were very shocked and disappointed.

Interviewer: How do you feel when you are writing down the mark?

Student (3): I think I don't know how to give myself a mark.

These students' confidence level is largely controlled by their past experiences with the subject and they are emotionally vulnerable.

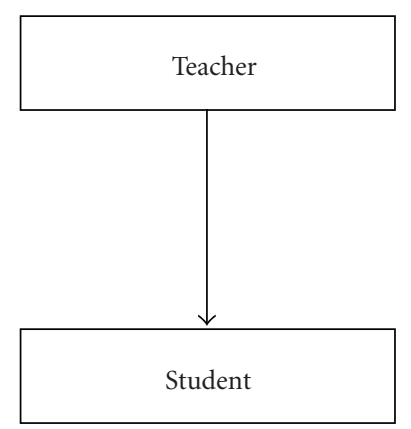

Figure 1: Teacher-student relationship in compliant selfassessment.

Interviewer: So if you give yourself 75 for Math but the teacher gives you 70 instead, will that still be helpful to you?

Student (3): No... it means the teacher look down on my math...I would lose hope (for the next paper).

These students' perception of what differentiates good and poor results are largely teacher controlled. These disempowered students' end objective in self-assessment is to seek compliance with the expectations set by the teacher.

Interviewer: When your teacher gives you a lower mark than what you have given yourself, how would you feel?

Student (13): I will feel disappointed and should have studied harder for that.

Students who experience compliant self-assessment focus on the teacher's expectations as the basis for self-assessment. They do not possess a personal understanding of what self-assessment entails. They merely seek to adhere to the teacher's expectations with no consideration of requisite standards and criteria against which they can use to judge their academic performance in the self-assessedtask.

Conception 2: Reliant Student Self-Assessment. In this conception, students do not simply conform to their teacher's 


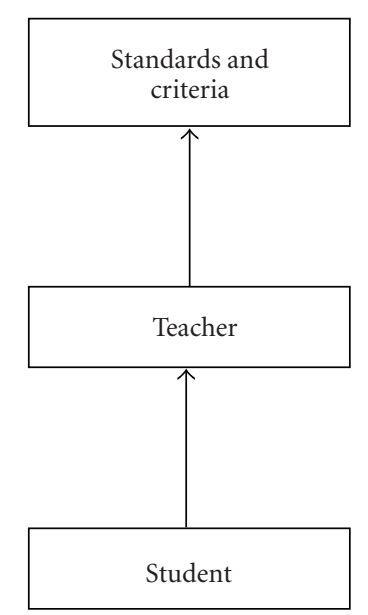

FIGURE 2: Teacher-mediated standards in reliant self-assessment.

expectations, but also appreciate that they need to understand the standards and criteria of the assessed task against which they should judge their learning. However, the students are hugely reliant on their teachers to explain what these standards and criteria should be. The standards and criteria are largely contained in written instruments such as assessment rubrics. The students accept that the assessment rubrics represent their teacher's expression of requisite standards and criteria, and they do not question these assessment rubrics in any way.

The teacher-student relationship in this conception may be illustrated by Figure 2 .

Students with a reliant conception of self-assessment are able to understand and subsequently accept the teacher's judgement and expectations.

Student (7): ...they (the teachers) have to mark according to how well we did.

Interviewer: So the teacher is always right?

Student (7): Yes...If we think that we write better, we can double check with the teacher and see what went wrong... they have to go through again to see if it is necessary to give a higher mark.

These students make attempts to understand what standards and criteria should mean for the self-assessed task, but they are more comfortable with following the teacher's interpretation or the benchmarks the teacher has set. They draw conclusions on their proficiency level based on the guidance provided by the teacher.

Student (7): They can help us see what are our strengths and weaknesses and encourage us to be more confident in ourselves.

Students with a reliant conception of self-assessment are made aware of the standards and criteria of the self-assessed task only by their teacher. The teacher plays an indispensable role in facilitating their understanding of epistemological framework. The teacher acts like a guardian of standards and criteria and these students base their self-assessment of their work on the teacher's interpretation of standards and criteria.

Student (1): There is a set of rubrics...The teachers usually give us a piece of rubrics for every major assignment and at least we have guidelines on how to do our project... these rubrics are being used by teachers (to determine) which criteria will reach which kind of mark....

References to past experiences are made for target setting and these students are not as overtly affected as students who practise compliant self-assessment.

Student (1): (The correct mindset for self-assessment is) if you score badly, then you should try to improve yourself and not feel too bad about it.

These students evaluate their achievement based on their understanding of the teacher-interpreted standards and criteria. Their end objective in self-assessment is to perform better to meet the teacher's standards. The focus is not to judge more accurately, but rather to improve their results.

Interviewer: Did you understand why you only get 22 instead of 28 after getting back the paper?

Student (11): I saw a lot of red lines in the paper and it's like my sentences are not complete...(I agree with my teacher) because some of my sentences are Singlish... (The teacher will be able to help me improve my score by teaching) words that can give the correct meaning and sentences that can be made to be more short and simple...

Students who experience reliant self-assessment focus on the teacher's standards which formed the basis for selfassessment. Unlike students in Conception 1, students in Conception 2 are able to move beyond teachers' expectations to take into consideration the teachers' interpretation of requisite standards and criteria. However, any personal judgment is generally subsumed under the perception that teacher possesses is an expert whose interpretation of standards is to be accepted without question.

Conception 3: Defiant Student Self-Assessment. In this conception, students go beyond understanding the teacher's interpretation of standards and criteria by contemplating what these should mean for themselves when self-assessing. While they are able to understand that assessment rubrics represent their teacher's expression of requisite standards and criteria, they question the varying standards teachers might have when it comes to interpreting such assessment rubrics.

Through initiating personal judgement of their academic performance, they are defiant of the teachers' monopoly of interpreting standards and criteria for their own selfassessment.

The teacher-student relationship in this conception may be illustrated by Figure 3 . 


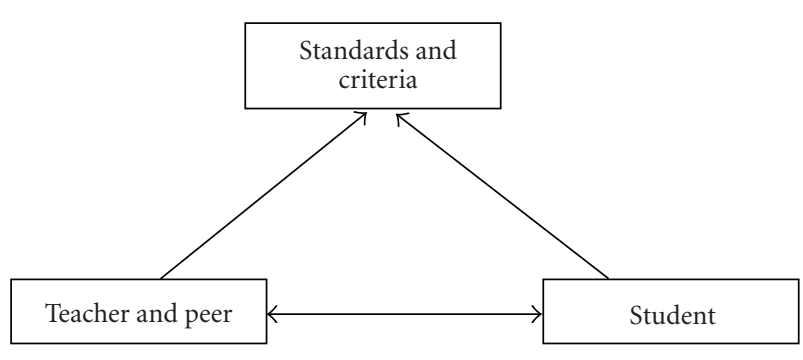

FIGURE 3: Students possess independent understanding and interpretation of standards.

Students with a defiant conception of self-assessment understand the teacher's expectations and judgement, but do not necessarily accept the teacher's expectations and judgement all the time.

Interviewer: Do you think your teacher is always correct in assessing your papers, say composition?

Student (6): If I were to have a chance to compare mine with others who scored higher, I would be able to see the things I have not done and the others who scored higher have. If I am convinced that I should get a lower mark, the teacher is correct in assessing my paper. If not, the teacher's grading is deemed to be questionable.

They are able to understand teacher-interpreted standards and criteria and take on dual perspectives when analysing the quality of the self-assessed task.

Student (15): I try to see my teacher's point of view and basically how much research I have done and how many different points of view that I have presented and for the overall on how the project do.

Through their personal interpretation of standards and criteria and comparison with their peers, they are able to make meaning of their academic performance and also judge this against the teacher's standards in self-assessment.

Student (15): ...I roughly gauge what are my marks because it is based not only on your own standard but also on what others submit. If the others' are better, then naturally yours will drop...(self-assessment.) gives me a rough idea of how I stood especially when I compare my own work to my classmates' work and I will know why there will be a difference in marks....

Student: ...You need to see what is the class standard...If you choose to compare, then you know which one will fall under which category...I think (teachers) roughly (have the standards in their minds) but students sometimes come out with pretty amazing things that can change their thinking.

Students with a defiant conception of self-assessment are aware of and understand the utility and purpose(s) of selfassessment. They self-assess based on their teacher's and self-interpreted standards and criteria. This group is also able to understand that different teachers may have different interpretations of standards.

Student (5): I think it depends on my performance and how I judge myself and sometimes I have to consider if the teacher is lenient or strict like for marking schemes and things like that because some papers are relative....

These students are not affected by their past experience:

Interviewer: So even though last time the difference between your mark and your teacher's mark is about $50 \%$, it won't affect you this time round?

Student (8): Yes.

These students do not see teachers as the sole players in the process of understanding epistemological framework. Students view themselves and the teacher as being mutually dependent in this process, and their end objective in selfassessment is to experience epistemology independently.

Interviewer: How is it (writing targeted mark before the paper and writing self-assessed mark) going to help you?

Student (5): Then you can see what went wrong and were your expectations too high and you can adjust accordingly... if the teacher's marks are higher than (my self assessed marks), I can try to put in more effort and the teacher's marks and the marks I want myself should be equal.

Students who experience defiant self-assessment focus on judging their own standards against the teacher's standards. The defiant nature of Conception 3 encompasses personal judgement which is missing from Conceptions 1 and 2. The students who possess this conception are more sophisticated in their understanding of the utility and purpose(s) of selfassessment and they appreciate the opportunity to exercise their own judgement in the self-assessment process.

Unlike students in Conceptions 1 and 2 who accept wholly what their teachers expect or interpret, they are more self-directed in their learning, and there will be occasions when they attempt to withstand the imposition of the teacher's interpretation of standards.

\section{Discussion}

The current study aims to clarify if ego type does affect selfassessment among secondary school students in Singapore. The grouping of students into three groups with high, medium/moderate, and low ego scores facilitated the ease of documenting the profiles of students with the same ego type and allowed for an in-depth understanding of how the accuracy of the self-assessment was affected by the student's ego. However, it is also clear from the study that it is important for teachers to possess and present clear and unambiguous standards for students to practice self-assessment to their own benefit. Such a practice of relying on standards for making judgments of students' learning is commonly referred 
to as standards-based assessment in contrast to norm-based assessment wherein students' learning is judged against other students and not against fixed standards [25].

Increasingly, standards-based assessment or the provision of clear and unambiguous descriptions of required standards of performance by teachers to students is being emphasised as good assessment practice. Hawe [26] describes standards-based assessment or standards-referenced assessment as emphasising "explicit specification of standards, the use of teachers' qualitative judgments and development of shared understandings regarding the interpretation and operationalisation of these standards" (page 94). Buckles et al. [27] argue that clear descriptions of standards of performance are important for informing students what they are expected to learn, how they should perform in their assessed work, and for informing teachers how they can assess students accordingly.

However, for students with a compliant conception of self-assessment, their perception of personal standards is determined by the teachers and they are likely to accept arbitrary grades, without being aware of it. Possibly due to their lack of confidence and low ego, students with a compliant conception of self-assessment rely on the teachers to give them the pointers for improving their test scores.

The form and tone of feedback for students with a compliant conception of self-assessment is also important. Teachers who focus their critical feedback on personal characteristics can be demotivating and can negatively affect ego [28]. These students are unable to build confidence from within and the teachers' encouragement plays a big role in this aspect.

Emotions and relationships surrounding past learning and assessment contexts can powerfully influence current perceptions of assessment and learning. In Crossman [29], students' accounts of relationships and emotions in shaping their perceptions of assessment reveal how students value opportunities to express their beliefs, feelings, and emotions during the assessment process. Such an opportunity would be invaluable for students with a complaint conception of self-assessment to build confidence in making and sharing judgments of their own learning. However, student's confidence in making and communicating judgments of their learning are greatly influenced by the power relationships in self-assessment practices.

The conventional argument has been that self-assessment counters the dominant influences of the teacher's power by allowing students to exercise some of that power for themselves. In this regard, reducing the teacher's power over students is a basis for the practice of student self-assessment [30-32]

In the past few years, some writers have questioned the assumption that self-assessment practices will automatically empower students in the assessment process $[15,16,33$, $34]$. These writers argue that the potential of student selfassessment to empower students for learning depends on how it is understood and used by academics and students. The findings of this study offer insights into the different ways that teachers may understand and use power in relation to enhancing their students' learning.
In Conception 1, compliant self-assessment focuses entirely on the teacher's expectations. Due to their lack of awareness of the utility and purpose(s) of self-assessment, these students are rendered completely powerless in the process of self-assessment. Even if the teacher wants to relinquish this power to them, it is unlikely that they are able to fully comprehend the essence of actual self-assessment.

The power relationship between the teacher and students with a compliant conception of self-assessment is an unambiguous "agent-recipient" type where the teacher, as an "agent/authority", possesses unrivalled power. This reflects students experiencing teachers as sole dominions of sovereign power in their self-assessment. The students' focus is on the teacher's retention and exercise of his or her commodity of sovereign power over students.

In Conception 2, reliant self-assessment focuses on accepting teacher's expectations and interpretation of standards and criteria and using them as yardsticks for evaluation. The influence of the teacher is extensive on these impressionable students. They are lost in the empowerment process because of their overreliance on the teacher.

Students with a reliant conception of self-assessment are aware of the need to understand standards against which they are to judge their learning against, and that these standards are not necessarily the same as the teacher's expectations. However, they assume teachers to assume epistemological power in dictating what constitutes knowledge (and standards).

In Conception 3, defiant self-assessment focuses on selfinterpreted standards and criteria and the students are always judging their own learning against their teacher's judgement. These students feel and want to be empowered by selfassessment. They are able to leverage on this opportunity given by the teachers to negotiate for what they think they deserve given their high level of confidence and awareness and understanding of the utility and purpose(s) of selfassessment.

For students with a defiant conception of self-assessment, there is more interaction between the teacher and the student when it comes to exploring the epistemology of requisite standards in the assessment task. These students value the opportunity to exercise their own judgment in the selfassessment process and are likely to refuse to be subjected to any possible arbitrary grading by the teachers.

\section{Conclusion}

Various writers have warned that it is naïve to assume that all students wish to be empowered in assessment $[33,35]$, and that all students are equally ready to exercise autonomy and self-regulation in self-assessment opportunities $[15,36]$. Both students and teachers bring with them learned notions of behaviour and power relations into the assessment process. Both may have been conditioned to accept entrenched roles in student assessment. The risk is that outwardly forms of greater student autonomy in the self-assessment process may be derailed by the inward tendencies of students to selfassess according to the teacher's preferences. 
Phenomenographic findings have been described as useful for assisting individuals to become aware of variation in the phenomenon by offering its research findings as a comparison with their personal ways of experiencing the same phenomenon. In a recent publication of extensive research on applications of variation theory, Marton and Tsui [37] explain the pedagogical potential of phenomenography for pedagogical approaches. Whilst previously phenomenography was understood as yielding a limited number of categories of description from which a phenomenon could be understood, Marton and Tsui [37] argue that "students understand that which they are supposed to learn in a limited number of different ways... and that (their) research shows that teachers who pay close attention to such differences (or variations), and who can build on students' prior understanding and experiences, are better able to bring about meaningful learning for their students." (page 194).

Tsui [38] identifies three necessary tasks for such learning to take place - that conditions should be present for learners to discern and hold in awareness the critical aspects of the object of their learning, that teacher's should be aware of their student's experience of the object of learning, and finally that teachers should widen the shared common ground in which students could experience the variation of awareness of the object of learning. Such common ground for learning is constructed and negotiated by assessment. It is argued that students can only learn to progress to a more advanced conception or readiness to learn if there is sufficient autonomy and clarity of standards for them to engage in their self-assessment.

This study has indicated that students may be at three different levels of readiness to engage their teachers in understanding and negotiating standards in self-assessment practices. It is not enough simply to tell students that they have the power to self-judge and self-value their learning. Teachers should also note that students have different levels of confidence in dealing with differences in student's and teachers' marks and in understanding requisite standards for selfassessment. Students need to be convinced, and then assisted, to exercise a form of autonomy in their assessment that runs counter to all their educational experiences of being assessed unilaterally. Such assistance and support should consider whether students may typically comply with teacher's expectations, rely on teachers for assessment standard or be able to defy teacher's imposition of standards in order to independently judge their learning in sustainable ways.

\section{References}

[1] J. Cowan, "Struggling with student self-assessment," in Developing Student Autonomy in Learning, D. Boud, Ed., Kogan Page, London, UK, 1988.

[2] A. A. Baniabdelrahman, "The effect of the use of selfassessment on EFL students' performance in reading comprehension in English," The Electronic Journal for English as a Second Language, vol. 14, no. 2, 2010.

[3] Y. G. Butler and J. Lee, "The effects of self-assessment among young learners of English," Language Testing, vol. 27, no. 1, pp. 5-31, 2010.
[4] H. G. Andrade, "Student self-assessment: at the intersection of metacognition and authentic assessment," in Proceedings of the Annual Meeting of the American Educational Research Association, ERIC Document Reproduction Service No. ED431030, Montreal, Canada, 1999.

[5] C. C. Chang and K. H. Tseng, "Use and performances of webbased portfolio assessment," British Journal of Educational Technology, vol. 40, no. 2, pp. 358-370, 2009.

[6] J. R. Ng and J. K. Earl, "Accuracy in self-assessment: the role of ability, feedback, self-efficacy and goal orientation," Australian Journal of Career Development, vol. 17, no. 3, pp. 39-50, 2008.

[7] F. X. Gibbons, "Self-attention and self-report: The 'verdicality' hypothesis," Journal of Personality, vol. 51, no. 3, pp. 517-542, 1983.

[8] M. D. N. Lew, W. A. M. Alwis, and H. G. Schmidt, "Accuracy of students' self-assessment and their beliefs about its utility," Assessment \& Evaluation in Higher Education, vol. 35, no. 2, pp. 135-156, 2010.

[9] Dictionary.com, 2010, http://dictionary.reference.com/.

[10] Collins English Dictionary Complete \& Unabridged, William Collins Sons \& Co. Ltd, London, UK, 10th edition, 2009.

[11] Merriam-Webster's Medical Dictionary, Merriam-Webster, Springfield, Mass, USA, 2007.

[12] D. Harper, Online Etymology Dictionary, 2010.

[13] M. Bürgy, "The narcissistic function in obsessive-compulsive neurosis," American Journal of Psychotherapy, vol. 55, no. 1, pp. 65-73, 2001.

[14] R. Paul and L. Elder, The Miniature Guide to Critical Thinking Concepts \& Tools. U.S., The Foundation for Critical Thinking, 2003.

[15] K. H. K. Tan, "Does student self-assessment empower or discipline students?" Assessment \& Evaluation in Higher Education, vol. 29, no. 6, pp. 651-662, 2004.

[16] M. Reynolds and K. Trehan, "Assessment: a critical perspective," Studies in Higher Education, vol. 25, no. 3, pp. 266-278, 2000.

[17] P. Ashworth and U. Lucas, "Achieving empathy and engagement: a practical approach to the design, conduct and reporting of phenomenographic research," Studies in Higher Education, vol. 25, no. 3, pp. 295-308, 2000.

[18] R. Saljo, "Talk as data and practice : a critical look at phenomenographic inquiry and the appeal to experience," Higher Education Research \& Development, vol. 16, no. 2, pp. 173-190, 1997.

[19] A. Barnard, H. McCosker, and R. Gerber, "Phenomenography: a qualitative research approach for exploring understanding in health care," Qualitative Health Research, vol. 9, no. 2, pp. 212226, 1999.

[20] F. Marton and S. Booth, Learning and Awareness, Lawrence Erlbaum, Mahwah, NJ, USA, 1997.

[21] T. Kroksmark, “Teaching and teachers' didaktik: outlines for a phenomenographic description of teachers' teaching competence," Studies in Philosophy and Education, vol. 14, no. 4, pp. 365-382, 1995.

[22] G. Åkerlind, "Variation and commonality in phenomenographic research methods," Higher Education Research \& Development, vol. 24, no. 4, pp. 321-334, 2005.

[23] F. Marton, G. Dall'alba, and E. Beaty, "Conceptions of learning," International Journal of Educational Research, vol. 19, pp. 277-300, 1993. 
[24] C. T. Teo, The OGE Adolescent Checklist, Singapore, 2007.

[25] K. H. K. Tan and M. Prosser, "Qualitatively different ways of differentiating student achievement: a phenomenographic study of grade descriptors," Assessment \& Evaluation in Higher Education, vol. 29, no. 3, pp. 267-282, 2004.

[26] E. Hawe, "Assessment in a pre-service teacher education programme: the rhetoric and the practice of standards-based assessment," Asia-Pacific Journal of Teacher Education, vol. 30, no. 1, pp. 93-106, 2002.

[27] S. Buckles, M. Schug, and M. Watts, "A national survey of state assessment practices in the social studies," Social Studies, vol. 92, no. 4, pp. 141-146, 2001.

[28] G. Gibbs and C. Simpson, "Conditions under which assessment supports students' learning," Learning and Teaching in Higher Education, vol. 1, no. 1, pp. 3-31, 2004.

[29] J. Crossman, "The role of relationships and emotions in student perceptions of learning and assessment," Assessment \& Evaluation in Higher Education, vol. 26, no. 3, pp. 313-327, 2007.

[30] D. Boud, Enhancing Learning through Self-Assessment, Kogan Page Limited, London, UK, 1995.

[31] A. C. Butcher and L. J. Stefani, "Analysis of peer, self- and staffassessment in group project work," Assessment in Education : Principle Policy \& Practice, vol. 2, no. 2, pp. 165-186, 1995.

[32] M. Hand, "Against autonomy as an educational aim," Oxford Review of Education, vol. 32, no. 4, pp. 535-550, 2006.

[33] M. Taras, "Issues of power and equity in two models of selfassessment," Teaching in Higher Education, vol. 13, no. 1, pp. 81-92, 2008.

[34] K. H. K. Tan, "Meanings and practices of power in academics' conceptions of student self-assessment," Teaching in Higher Education, vol. 14, no. 4, pp. 361-373, 2009.

[35] L. Leach, G. Neutze, and N. Zepke, "Assessment and empowerment: some critical questions," Assessment and Evaluation in Higher Education, vol. 26, no. 4, pp. 293-305, 2001.

[36] N. Pope, "The impact of stress in self- and peer-assessment," Assessment \& Evaluation in Higher Education, vol. 30, no. 1, pp. 51-63, 2005.

[37] F. Marton and A. Tsui, Classroom Discourse and the Space of Learning, Lawrence Erlbaum Associates, Hillsdale, NJ, USA, 2004.

[38] A. Tsui, "The shared space of learning," in Classroom Discourse and the Space of Learning, F. Marton and A. Tsui, Eds., pp. 165186, Lawrence Erlbaum Associates, Mahwah, NJ, USA, 2004. 


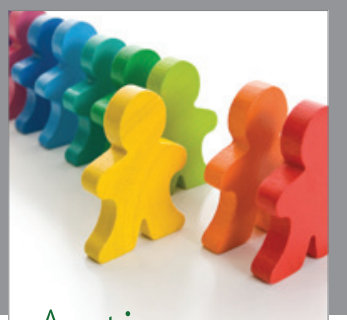

Autism

Research and Treatment
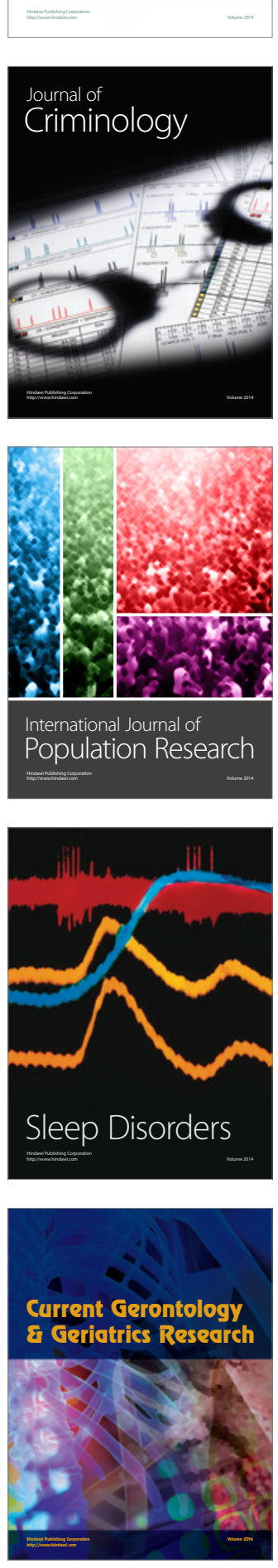
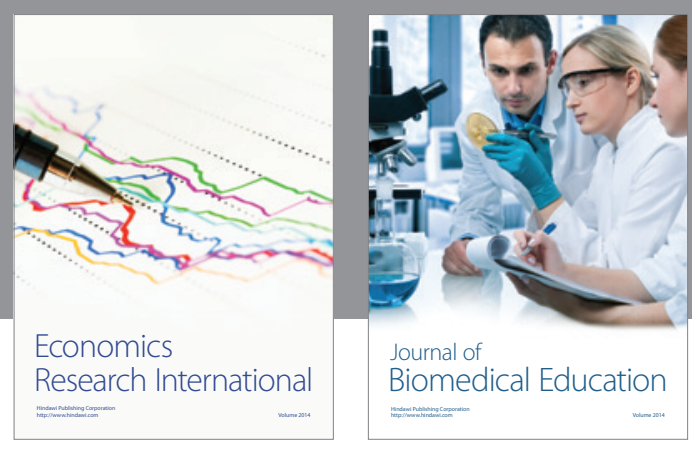

Journal of

Biomedical Education

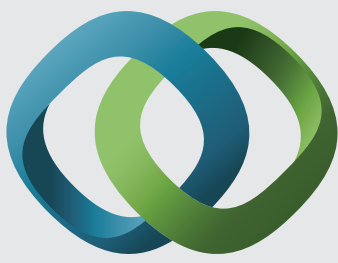

\section{Hindawi}

Submit your manuscripts at

http://www.hindawi.com
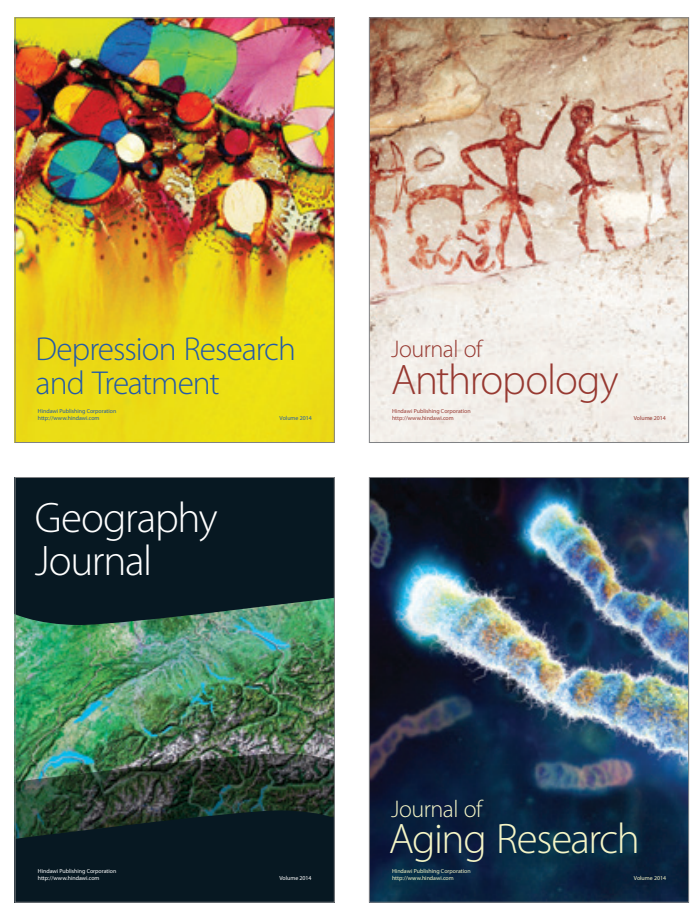

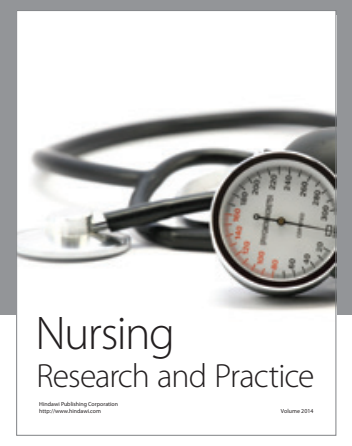

Nursing

Research and Practice

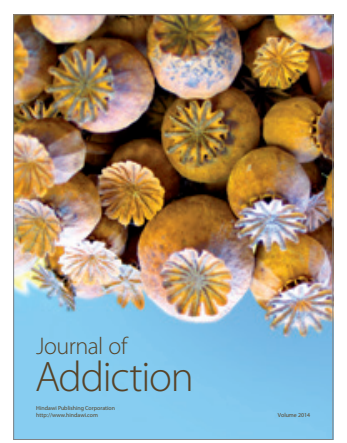

Child Development

Research

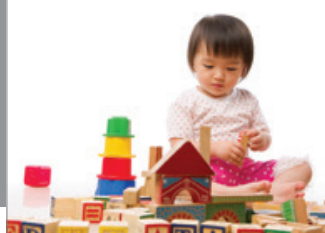

迥
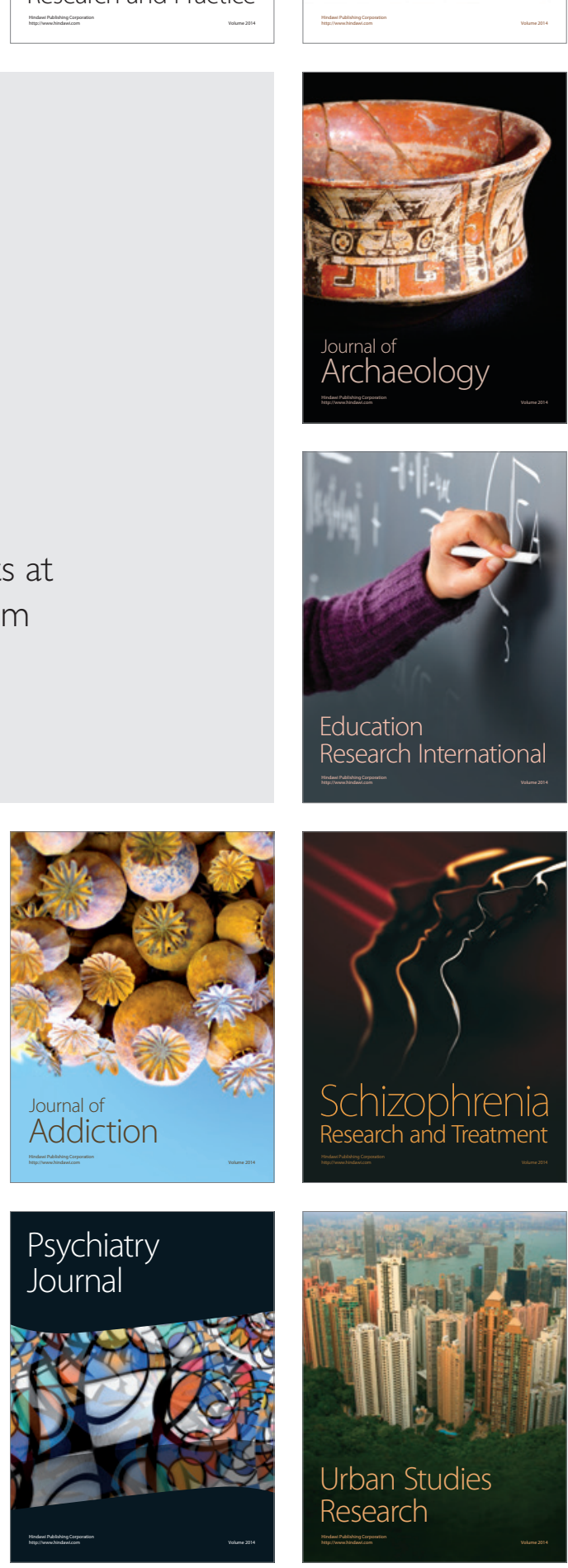